\title{
Overview of Gestational Diabetes Mellitus (GDM) in Ghana; a Call for Action
}

\author{
Dan Yedu Quansah ${ }^{1 *}$, Daniel Boateng ${ }^{2}$ and Louis Boafo Kwantwi ${ }^{3}$ \\ ${ }^{1}$ Department of Biomedical Sciences, School of Allied Health Sciences, University of Cape Coast, Ghana \\ ${ }^{2}$ School of Public Health, Kwame Nkrumah University of Science and Technology, Ghana \\ ${ }^{3}$ Department of Molecular Medicine, Kwame Nkrumah University of Science and Technology, Ghana
}

Submission: March 13, 2018; Published: March 27, 2018

*Corresponding author: Dan Yedu Quansah, Department of Biomedical Sciences, School of Allied Health Sciences, University of Cape Coast, Cape Coast, Ghana, Email: dan_quansah@yahoo.com

\section{Opinion}

Gestational diabetes mellitus (GDM), known as glucose intolerance, diagnosed for the first time in pregnancy usually occurs between 24 and 28 weeks of gestation [1,2]. The international diabetes federation (IDF) asserts that, globally, one in 7 births was diagnosed of GDM in 2017 [3]. GDM can results in several pregnancy complications such as increased blood pressure, large birth weight babies and obstructed labor. A systematic review and meta-analysis of published studies on GDM estimated the prevalence of GDM in sub-Saharan Africa to be about $14 \%$ in 2015 [4]. Significant risk factors of GDM includes, overweight and or obesity, family history of diabetes, previous birth compilations, previous child with large birth weight and pregnant women who are advanced (more than 30 years) in age [4].

There is a significant relationship between GDM and the development of type-2 diabetes [3]. A previous diagnosis of GDM is associated with $60 \%$ risk of developing type-2 diabetes [5]. In a 10 year follow up study of women who delivered in 2010 [6] women diagnosed of GDM had 10 times increased risk of developing type- 2 diabetes. GDM women with high body mass index, family history of diabetes, non-white ethnicity, advanced maternal age, raised fasting glucose and increased HbA1c have higher risk of type-2 diabetes [7-12].

Gestational diabetes is strongly associated with obesity and type-2 diabetes [13-16]. The prevalence and risk factors of type 2 diabetes is well established among the Ghanaian adult population. A recent systematic review and meta-analysis of primary studies put the prevalence of obesity at $43 \%$, with a higher prevalence found in women [17]. The prevalence of diabetes among adult population was also found to be $3.6 \%$ in 2017 [3]. The 2014 Ghana demographic and health survey (GDHS) revealed that four out of ten women were either overweight or obese [18]. A trend analysis shows an increasing prevalence of overweight and obesity from 25\% in 2003 to $40 \%$ in 2014 [18]. Despite the increasing prevalence of obesity and T2D among women of reproductive age in Ghana, the national prevalence of GDM is not known. Extrapolated statistics on gestational diabetes indicates a $0.5 \%$ prevalence in 2004 [11] in Ghana. An independent study in 2013 found a 9.3\% prevalence of GDM among women attending prenatal care [12] in a tertiary Hospital in Ghana. Knowledge of GDM is also low among pregnant women. This could be partly due to the ineffective policy, monitoring and surveillance of GDM in Ghana [19]. Even though there is a diabetes framework, a policy for diabetes monitoring, surveillance and treatment in Ghana, this framework is designed to focus only on type-2 diabetes [19]. This calls for a proper policy to look at diabetes with a holistic perspective. With the development of a proper and effective national diabetes plan in sight, it is important that GDM and its modifiable risk factors such as obesity, lifestyle and dietary factors are given the needed attention. Due to the inexistence of a defined guideline for GDM screening in Ghana [12], GDM is diagnosed by relying on patient's history of diabetes, or pregnancy related complications or onset of diabetes symptoms. It is imperative to provide at least an oral glucose tolerance test (OGTT) at 24 to 28 weeks of gestation as part of antenatal care in order to identify, treat and manage GDM rather than relying on history of diabetes, onset of diabetes symptoms and pregnancy complication. This will provide data on GDM prevalence as well as help improve intervention efforts.

Ghana will experience adverse health challenges such as increased prevalence of co-morbidities associated with GDM if this current trend continues. Women with GDM are at risk of pre-eclampsia, primary cesarean delivery, preterm delivery for the mother and macrosomia, neonatal hypoglycemia, birth injury, respiratory problems, hyperbilirubinemia, hypocalcemia, intensive care for the child $[20,21]$. Long term maternal risks 


\section{Current Research in Diabetes \& Obesity Journal}

such as GDM recurrence, 5-10 year risk of type-2 diabetes or an increased risk of metabolic syndrome and cardiovascular disease [20,22] are also associated with GDM. Increasing evidence suggest that, one-third of women with recent GDM develop postpartum depression [21]. Postpartum depression may results in decrease in physical activity, paving way for comfort eating, which ultimately increases the risk of weight gain $[23,24]$.

The management of GDM emphasizes on glycemic control. Glycemic control is achieved through lifestyle interventions such as dietary modifications and physical activity. Drug therapy such as insulin injections and other hypoglycemic agents are relied on when these interventions are unsuccessful in achieving glycemic control. In Ghana however, hypoglycemic agents such as insulin and metformin are the focus of GDM treatment [25]. Until recently, metformin was not administered in Ghana [12] Whiles it is certainly okay to administer these hypoglycemic agents, emphasis must be placed on dietary and physical activity interventions. Even though some epidemiological studies have identified the risk factors associated with GDM, experiences of women with GDM and the nutritional status of women with GDM in Ghana [26-29], none of these studies have looked at interventions such as physical activity, nutritional and lifestyle modifications and GDM. In short there is lack of information on GDM in Ghana. There is the need for both epidemiological and intervention researches that will provide evidence on the burden of GDM and management of the risk factors to arrest it's long and short term effects. Nutritional and lifestyle interventions such as decreasing fat intake especially saturated fat, which is a risk factor for both GDM and type-2 diabetes [30] is seen as one of the ways to achieve glycemic control. Recently, a review of literature showed that consumption of diets rich in antioxidants, including Vitamin $\mathrm{E}$ and A could reduce the risk of GDM [31]. Increasing physical activity may improve glycemic control and/or limit insulin use in women with GDM. Regular physical activity presents a classical way to sustain pregnancy weight gain [32], stabilize maternal mood, and limit fetal fat mass and physiological stress responses in the offspring. The lack of research evidence on GDM in Ghana will hamper efforts targeted at addressing GDM and its related risks.

Our opinion is strongly stated on the need for a national screening policy and effective management of GDM in Ghana. With this strong opinion we anticipate an incorporation of a GDM policy in the much anticipated national diabetes plan as well as the need to provide funding for intervention research that focuses on the modifiable risk factors of GDM such as obesity, lifestyle and dietary factors. These interventions must be initiated at both the gestational and postpartum periods. These periods are known to be critical to change outcomes for both the mother and the offspring. An effective policy for GDM research and treatment may lead to breakthroughs in modern medical practices and clinical recommendations to manage and prevent gestational diabetes in Ghana.

\section{References}

1. Zawiejska A, Wender Ozegowska E, Brazert J, Sodowski K (2008) Components of Metabolic Syndrome and their impact on fetal growth in women with gestational diabetes mellitus. J Physiol Pharmacol 59 Suppl 4: 5-18.

2. American Diabetes Association (2004) Gestational diabetes mellitus. Diabetes Care 27: 88-90.

3. International Diabetes Federation (2017) IDF Diabetes Atlas. $\left(8^{\text {th }}\right.$ edn), Brussels, Belgium.

4. Mwanri AW, Kinabo J, Ramaiya K, Feskens EJM (2015) Gestational diabetes mellitus in sub-Saharan Africa: systematic review and metaregression on prevalence and risk factors. Trop Med Int Heal 20(8): 983-1002.

5. Noctor E, Dunne FP (2015) Type 2 diabetes after gestational diabetes: The influence of changing diagnostic criteria. World J Diabetes 6(2): 234-244.

6. Herath H, Herath R, Wickremasinghe R (2017) Gestational diabetes mellitus and risk of type 2 diabetes 10 years after the index pregnancy in Sri Lankan women-a community based retrospective cohort study. PLoS One 12(6): e0179647.

7. Rayanagoudar G, Hashi AA, Zamora J, Khan KS, Hitman GA, (2016) Quantification of the type 2 diabetes risk in women with gestational diabetes: a systematic review and meta-analysis of 95,750 women. Diabetologia 59(7): 1403-1411.

8. Amoah AG, Owusu SK, Adjei S (2002) Diabetes in Ghana: a community based prevalence study in Greater Accra. Diabetes Res Clin Pr 56(3): 197-205.

9. Gatimu SM, Milimo BW, Sebastian MS (2016) Prevalence and determinants of diabetes among older adults in Ghana. BMC Public Health 16: 1174.

10. Danquah I, Bedu Addo G, Terpe K, Micah F, Amoako YA, et al. (2012) Diabetes mellitus type 2 in urban Ghana: characteristics and associated factors. BMC Public Health 12: 210.

11. Health grades International (2004) Statistics by country for gestational diabetes.

12. Oppong SA, Ntumy MY, Amoakoh Coleman M, Ogum Alangea $D_{,}$ Modey Amoah E (2015) Gestational diabetes mellitus among women attending prenatal care at Korle-Bu Teaching Hospital, Accra, Ghana. Int J Gynecol Obstet 131(3): 246-250.

13. Ben Haroush A, Yogev Y, Hod M (2015) Epidemiology of gestational diabetes mellitus and its association with Type 2 diabetes. Diabet Med 21(2): 103-113.

14. Berkowitz GS, Lapinski RH, Wein R, Lee D (1992) Race/ethnicity and other risk factors for gestational diabetes. Am J Epidemiol 135(9): 965-973.

15. Metzger BE, Buchanan TA, Coustan DR deLeiva A, Dunger DB, Hadden DR, et al. (2007) Summary and recommendations of the Fifth International Workshop-Conference on Gestational Diabetes Mellitus. Diabetes Care 30 Suppl 2: S251-S260.

16. Martin AO, Simpson JL, Ober C Freinkel N (1985) Frequency of diabetes mellitus in mothers of probands with gestational diabetes: possible maternal influence on the predisposition to gestational diabetes. Am J Obs Gynecol 151(4): 471-475.

17. Ofori Asenso R, Agyeman AA, Laar A, Boateng D (2016) Overweight and obesity epidemic in Ghana-a systematic review and metaanalysis. BMC Public Health 16(1): 1239.

18. (2015) Ghana Health Service (GHS) 2014 Ghana Demographic and Health Survey (DHS) Key Findings Rockville, Maryland, USA. 


\section{Current Research in Diabetes \& Obesity Journal}

19. Dake F (2013) Obesity among Ghanaian women: past prevalence, future incidence. Public Health 127(6): 590-592.

20. Lauenborg J, Hansen T, Jensen DM, Vestergaard H, Mølsted Pedersen L, et al. (2004) Population, Increasing Incidence of Diabetes after Gestational Diabetes a long-term follow-up in a Danish. Diabetes Care 27(5): 1194-1199.

21. Nicklas JM, Miller LJ, Zera CA, Davis RB, Levkoff SE, et al. (2013) Factors Associated with Depressive Symptoms in the Early Postpartum Period Among Women with Recent Gestational Diabetes Mellitus. Matern Child Health J 17(9): 1665-1672.

22. Bellamy L, Casas JP, HIngorani AD, Williams D (2009) Type 2 diabetes mellitus after gestational diabetes: a systematic review and metaanalysis. Lancet 373(9677): 1773-1779.

23. Linde JA, Jeffery RW, Levy RL, Sherwood NE, Utter J, et al. (2004) Binge eating disorder, weight control self-efficacy, and depression in overweight men and women. Int J Obes Relat Metab Disord 28(3): 418-425.

24. Carter AS, Baker CW, Brownell KD (2000) Body mass index, eating attitudes and symptoms of depression and anxiety in pregnancy and the postpartum period. Psychosom Med 62(2): 264-270.

25. Beyuo T, Obed SA, Adjepong Yamoah KK, Bugyei KA, Oppong SA, et al. (2015) Metformin versus Insulin in the Management of PreGestational Diabetes Mellitus in Pregnancy and Gestational Diabetes Mellitus at the Korle Bu Teaching Hospital: A Randomized Clinical Trial. PLoS ONE 10(5): e0125712.
26. Asare Anane H, Bawah AT, Osa Andrews B, Adanu R, Ofori EK, et al (2013) Lipid Profile In Ghanaian Women With Gestational Diabetes Mellitus. Int J Sci Technol Res 2(4): 168-175.

27. Oppong SA, Ntumy MY, Amoakoh Coleman M, Ogum Alangea D, Modey Amoah E (2015) Gestational diabetes mellitus among women attending prenatal care at Korle-Bu Teaching Hospital, Accra, Ghana. Int J Gynecol Obstet 131(3): 246-250.

28. Asare Anane H, Bawah AT, Ofori EK, Amanquah SD (2014) Risk Factors for Gestational Diabetes Mellitus among Ghanaian Women at the Korle-Bu Teaching Hospital. J Biol 4(12): 54-57.

29. Mensah GP, Affram CK, Richter S, Banful R (2017) Experiences of mothers with gestational diabetes in Ghana. Journal of Research in Nursing and Midwifery 6(2): 25-32.

30. Harrod CS, Chasan Taber L, Reynolds RM, Fingerlin TE, Glueck DH, et al. (2014) Physical Activity in Pregnancy and Neonatal Body Composition: The Healthy Start Study. Obstet Gynecol 124(2 Pt 1): 257-264.

31. Boateng D, Quansah DY (2016) Influence of Antioxidant Intake on Gestational Diabetes Mellitus : Evidence from published studies. SM Journal of Community Med 2(2).

32. Ruchat SM Mottola MF (2013) The important role of physical activity in the prevention and management of gestational diabetes mellitus. Diabetes Metab Res Rev 29(5): 334-346.

Your next submission with Juniper Publishers
will reach you the below assets
- Quality Editorial service
- Swift Peer Review
- Reprints availability
- E-prints Service
- Manuscript Podcast for convenient understanding
- Global attainment for your research
- Manuscript accessibility in different formats
( Pdf, E-pub, Full Text, Audio)
- Unceasing customer service
Track the below URL for one-step submission
https://juniperpublishers.com/online-submission.php

